\title{
Trading Volume and Serial Correlation in Stock Returns
}

\section{Citation}

Campbell, John Y., Sanford J. Grossman, and Jiang Wang. 1993. Trading volume and serial correlation in stock returns. Quarterly Journal of Economics 108, no. 4: 905-939.

\section{Published Version}

http://dx.doi.org/10.2307/2118454

\section{Permanent link}

http://nrs.harvard.edu/urn-3:HUL.InstRepos:3128710

\section{Terms of Use}

This article was downloaded from Harvard University's DASH repository, and is made available under the terms and conditions applicable to Other Posted Material, as set forth at http:// nrs.harvard.edu/urn-3:HUL.InstRepos:dash.current.terms-of-use\#LAA

\section{Share Your Story}

The Harvard community has made this article openly available.

Please share how this access benefits you. Submit a story.

Accessibility 


\title{
TRADING VOLUME AND SERIAL CORRELATION IN STOCK RETURNS*
}

\author{
JOHN Y. CAMPBELL \\ SANFORD J. GROSSMAN \\ JIANG WANG
}

This paper investigates the relationship between aggregate stock market trading volume and the serial correlation of daily stock returns. For both stock indexes and individual large stocks, the first-order daily return autocorrelation tends to decline with volume. The paper explains this phenomenon using a model in which risk-averse "market makers" accommodate buying or selling pressure from "liquidity" or "noninformational" traders. Changing expected stock returns reward market makers for playing this role. The model implies that a stock price decline on a high-volume day is more likely than a stock price decline on a low-volume day to be associated with an increase in the expected stock return.

\section{INTRODUCTION}

There is now considerable evidence that the expected return on the aggregate stock market varies through time. One interpretation of this fact is that it results from the interaction between different groups of investors. Suppose that some investors, "liquidity" or more generally "noninformational" traders, desire to sell stock for exogenous reasons. Other investors are risk-averse utility maximizers; they are willing to accommodate the selling pressure, but they demand a reward in the form of a lower stock price and a higher expected stock return. If these investors accommodate the fluctuations in noninformational traders' demand for stock, then they can be thought of as "market makers" in the sense of Grossman and Miller [1988], even though they may hold positions for relatively long periods of time and may not be specialists on the exchange. ${ }^{1}$

It is hard to test this view of the stock market using data on stock returns alone, because very different models can have similar

*We thank J. Harold Mulherin and Mason Gerety for providing data on daily NYSE volume, G. William Schwert for providing daily stock return data, Martin Lettau for correcting an error in the theoretical model, Ludger Hentschel for able research assistance throughout this project, and four anonymous referees and seminar participants at Princeton University and the 1991 NBER Summer Institute for helpful comments. Campbell acknowledges financial support from the National Science Foundation and the Sloan Foundation. Wang acknowledges support from the Nanyang Technological University Career Development Assistant Professorship at the Sloan School of Management.

1. See also Campbell and Kyle [1993]; De Long, Shleifer, Summers, and Waldmann [1989, 1990]; Shiller [1984]; Wang [1993a, 1993b]; and others.

- 1993 by the President and Fellows of Harvard College and the Massachusetts Institute of Technology.

The Quarterly Journal of Economics, November 1993 
implications for the time-series behavior of returns. In this paper we use data on stock market trading volume to help solve this identification problem. The simple intuition underlying our work is as follows. Suppose that one observes a fall in stock prices. This could be due to public information that has caused all investors to reduce their valuation of the stock market, or it could be due to exogenous selling pressure by noninformational traders. In the former case, there is no reason why the expected return on the stock market should have changed. In the latter case, market makers buying stock will require a higher expected return, so there will tend to be price increases on subsequent days. The two cases can be distinguished by looking at trading volume. If public information has arrived, there is no reason to expect a high volume of trade, whereas selling pressure by noninformational traders must reveal itself in unusual volume. Thus, the model with heterogeneous investors suggests that price changes accompanied by high volume will tend to be reversed; this will be less true of price changes on days with low volume.

Shifts in the demand for stock by noninformational traders can occur at low frequencies or at high frequencies. Daily trading volume is a signal for high frequency shifts in demand. Changes in demand that occur slowly through time are harder to detect using volume data because there are trends in volume associated with other phenomena such as the deregulation of commissions and the growth of institutional trading. We therefore focus on daily trading volume and the serial correlation of daily returns on stock indexes and individual stocks. Daily index autocorrelations are predominantly positive [Conrad and Kaul, 1988; Lo and MacKinlay, 1988], but our theory predicts that they will be less positive on highvolume days.

The literature on stock market trading volume is extensive, but is mostly concerned with the relationship between volume and the volatility of stock returns. Numerous papers have documented the fact that high stock market volume is associated with volatile returns; October 19,1987, is only the best known example of a pervasive phenomenon. ${ }^{2}$ It has also been noted that volume tends to be higher when stock prices are increasing than when prices are falling.

2. See Gallant, Rossi, and Tauchen [1992]; Harris [1987]; Jain and Joh [1988]; Jones, Kaul, and Lipson [1991]; Mulherin and Gerety [1989]; Tauchen and Pitts [1983]; and the survey in Karpoff [1987]. Lamoureux and Lastrapes [1990] argue that serial correlation in volume accounts for the serial correlation in volatility which is often described using ARCH models. 
In contrast, there is almost no work relating the serial correlation of stock returns to the level of volume. One exception is Morse [1980], who studies the serial correlation of returns in high-volume periods for $\mathbf{5 0}$ individual securities. He finds that high-volume periods tend to have positively autocorrelated returns, but he does not compare high-volume with low-volume periods. ${ }^{3}$ Several recent papers study serial correlation in relation to volatility: LeBaron [1992a] and Sentana and Wadhwani [1992], for example, show that the autocorrelations of daily stock returns change with the variance of returns. Below, we compare the effects of volume and volatility on stock return autocorrelations.

The organization of our paper is as follows. In Section II we conduct a preliminary exploration of the relation between volume, volatility, and the serial correlation of stock returns. In Section III we present a theoretical model of stock returns and trading volume. In Section IV we show that the model can generate autocorrelation patterns similar to those found in the actual data. We use both approximate analytical methods and numerical simulation methods to make this point. Section $V$ concludes.

\section{Volume, Volatility, and Serial Correlation: A PrELIMINARY EXPLORATION}

\section{A. Measurement Issues}

The main return series used in this paper is the daily return on a value-weighted index of stocks traded on the New York Stock Exchange and American Stock Exchange, measured by the Center for Research in Security Prices (CRSP) at the University of Chicago over the period $7 / 3 / 62$ through $12 / 30 / 88$. Results with daily data over this period are likely to be dominated by a few observations around the stock market crash of October 19, 1987. For this reason, the main sample period we use in this paper is a shorter period running from 7/3/62 through 9/30/87 (1962-1987 for short, or sample A). We break this period into two subsamples: $7 / 3 / 62$ through $12 / 31 / 74$ (1962-1974 for short, or sample B), which is the first half of the shorter sample and which excludes the

3. Some other papers have come to our attention since the first draft of this paper was written. Duffee [1992] studies the relation between serial correlation and trading volume in aggregate monthly data, while LeBaron [1992b] uses nonparametric methods to characterize the aggregate daily relation more accurately. Conrad, Hameed, and Niden [1992] study the relation between individual stocks' return autocorrelations and the trading volume in those stocks. 
period of flexible commissions on the New York Stock Exchange; and 1/2/75 through 9/30/87 (1975-1987 for short, or sample C), which is the remainder of the shorter sample period. Finally, we use the complete data set through the end of 1988 in order to see whether the extreme movements of price and volume in late 1987 strengthen or weaken the results we obtain in our other samples. We call this long sample 1962-1988 for short, or sample D.

We also study the behavior of some other stock return series. For the period before CRSP daily data begin, Schwert [1990] has constructed daily returns on an index comparable to the Standard and Poors 500. We use this series over the period 1/2/26-6/29/62. The behavior of large stocks is of particular interest, since measured returns on these stocks are unlikely to be affected by nonsynchronous trading. The Dow Jones Industrial Average is the best known large stock price index, and so we study its changes over the period 1962-1988. Individual stock returns also provide useful evidence robust to nonosynchronous trading, so we study the returns on 32 large stocks that were traded throughout the 1962-1988 period and were among the 100 largest stocks on both $7 / 2 / 62$ and $12 / 30 / 88 .^{4}$

Stock market trading volume data were kindly provided to us by J. Harold Mulherin and Mason S. Gerety. These researchers collected data from The Wall Street Journal and Barron's on the number of shares traded daily on the New York Stock Exchange from 1900 through 1988. They also collected data on the number of shares outstanding on the New York Stock Exchange. For a detailed description of their data, see Mulherin and Gerety [1989].

The ratio of the number of shares traded to the number of shares outstanding is known as turnover, or sometimes as relative volume. Turnover is used as the volume measure in most previous studies (for example, Jain and Joh [1988] and Mulherin and Gerety [1989]). Since the number of shares outstanding and the number of shares traded have both grown steadily over time, the use of turnover helps to reduce the low-frequency variation in the series. It does not eliminate it completely, however, as can be seen from the plot of the series presented in Figure I. Turnover has an upward trend in the late 1960s and in the period between the

4. The 32 stocks are American Home Products, AT\&T, Amoco, Caterpillar, Chevron, Coca Cola, Commonwealth Edison, Dow Chemical, Du Pont, Eastman Kodak, Exxon, Ford, GTE, General Electric, General Motors, ITT, Imperial Oil, IBM, Merck, 3M, Mobil, Pacific Gas and Electric, Pfizer, Procter and Gamble, RJR Nabisco, Royal Dutch Petroleum, SCE, Sears Roebuck, Southern, Texaco, USX, and Westinghouse. 


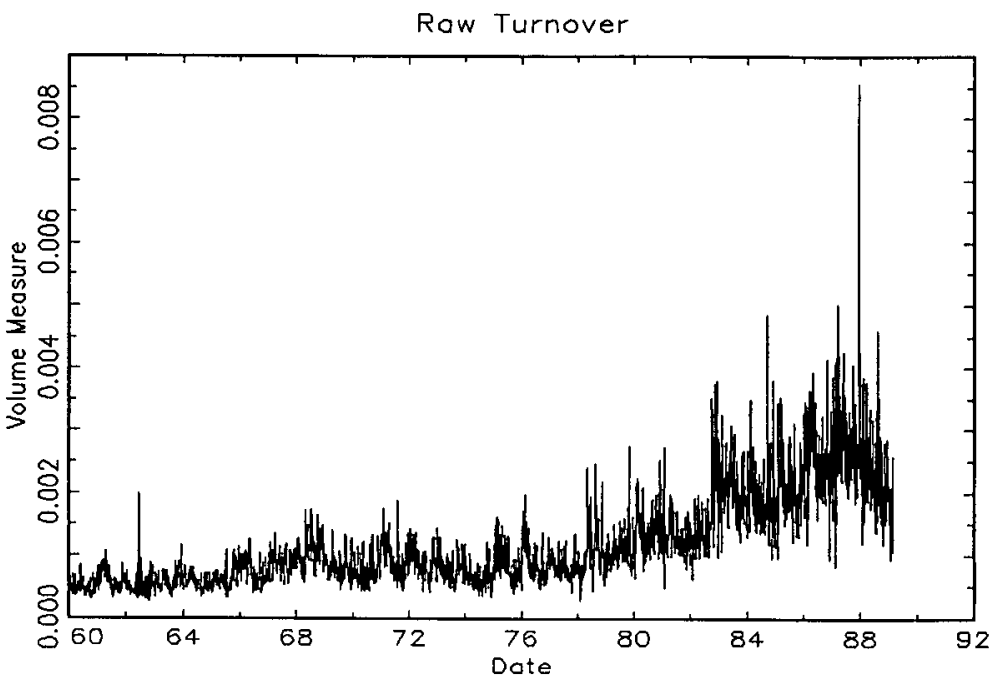

Figure I

Level of Stock Market Turnover, 1960-1988

elimination of fixed commissions in 1975 and the stock market crash of 1987. The growth of turnover in the 1980s may be due in part to technological innovations that have lowered transactions costs. In addition, the variance of turnover seems to increase with its level during the 1980 s.

In our empirical work, we want to work with stationary time series. When we relate our empirical results to our theoretical model, we want to measure trading volume relative to the capacity of the market to absorb volume. For both these reasons we wish to remove the low-frequency variations from the level and variance of the turnover series. To remove low-frequency variations from the variance, we measure turnover in logs rather than in absolute units. To detrend the log turnover series, we subtract a one-year backward moving average of log turnover. This gives a triangular moving average of turnover growth rates, similar to the geometrically declining average of turnover growth rates used by Schwert [1989] to explain stock return volatility. We explore some alternative detrending procedures below.

Our detrended volume measure is plotted in Figure II. The figure shows no trends in mean or variance, but it does show considerable persistence. The first daily autocorrelation of detrended volume is about 0.7 , and the fifth daily autocorrelation is 


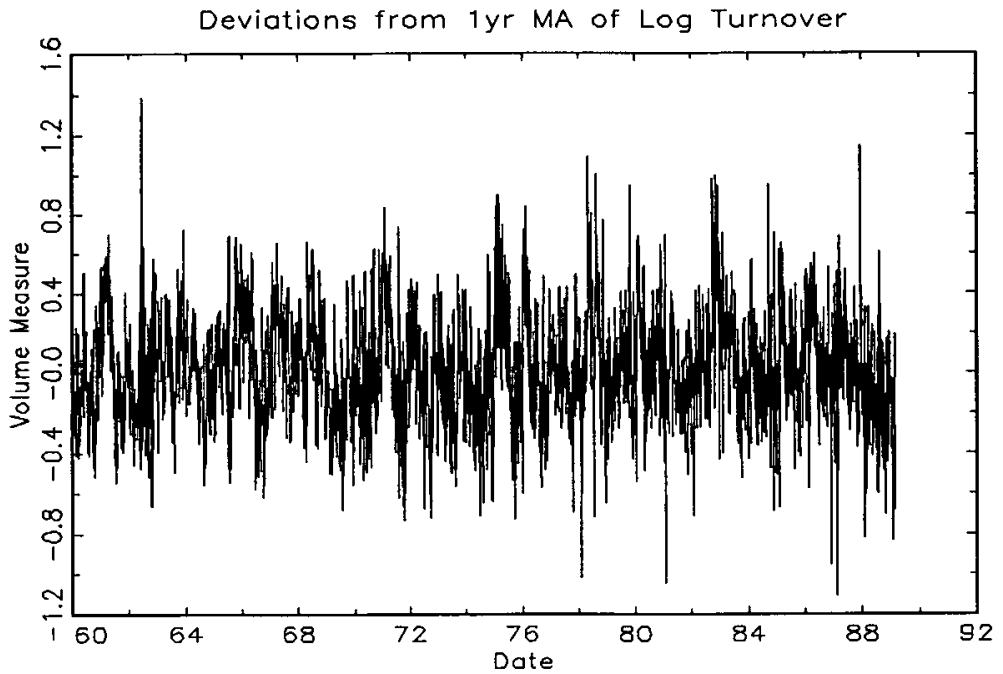

Figure II

Detrended Log Turnover, 1960-1988

still about 0.5 . The standard deviation of the series is close to 0.25 ; all these moments are stable across subsamples.

We also need a measure of stock return volatility. We take the conditional variance series estimated by Campbell and Hentschel [1992] using daily return data over the period 1926-1988. Campbell and Hentschel used a quadratic generalized autoregressive heteroskedasticity (QGARCH) model with one autoregressive term, two moving average terms, and a mean return assumed to change in proportion to volatility. The QGARCH model is very similar to the standard GARCH model of changing volatility, but it allows negative returns to increase volatility more than positive returns do.

\section{B. Forecasting Returns from Lagged Returns, Volatility, and Volume}

Table I summarizes the evidence on the first daily autocorrelation of the value-weighted index return. For each of our four sample periods, the table reports the autocorrelation with a heteroskedasticity-consistent standard error, and the $R^{2}$ statistic for a regression of the one-day-ahead return on a constant and the return. This statistic, which we write as $R^{2}(1)$ in the table, is just the square of the autocorrelation. The remarkable fact is that the 
TABLE I

(1)

The First Autocorrelation of Stock Returns

(2)

$$
\begin{gathered}
r_{t+1}=\alpha+\beta r_{t} \\
r_{t+1}=\alpha+\left(\Sigma_{i=1}^{5} \beta_{i} D_{i}\right) r_{t}
\end{gathered}
$$

\begin{tabular}{|c|c|c|c|}
\hline Sample period & $\begin{array}{c}\beta \\
\text { (s.e.) }\end{array}$ & $R^{2}(1)$ & $R^{2}(2)$ \\
\hline A: $7 / 3 / 62-9 / 30 / 87$ & $\begin{array}{c}0.219 \\
(0.016)\end{array}$ & 0.048 & 0.057 \\
\hline B: $7 / 3 / 62-12 / 31 / 74$ & $\begin{array}{c}0.280 \\
(0.026)\end{array}$ & 0.079 & 0.084 \\
\hline $\mathrm{C}: 1 / 2 / 75-9 / 30 / 87$ & $\begin{array}{c}0.166 \\
(0.020)\end{array}$ & 0.028 & 0.043 \\
\hline D: $7 / 3 / 62-12 / 30 / 88$ & $\begin{array}{c}0.190 \\
(0.036)\end{array}$ & 0.036 & 0.058 \\
\hline
\end{tabular}

autocorrelation exceeds 0.15 in every sample period; it is about 0.2 over the full sample and nearly 0.3 in the 1962-1974 period.

Table I also shows the improvement in $R^{2}$ that can be obtained by allowing the first autocorrelation to vary with the day of the week. A regression of the one-day-ahead return on the current return interacted with five day-of-the-week dummies has an $R^{2}$ statistic, labeled $R^{2}(2)$ in the table, that is at least 0.5 percentage points larger than the $R^{2}$ of the basic regression. The increase in $R^{2}$ is even greater in the 1962-1988 period, but much of this is due to the single week of the stock market crash. The day-of-the-week dummies are significant enough that we include them in all our subsequent regressions.

Table II looks at the relationship between volume and the first autocorrelation of the value-weighted index return. We regress the one-day-ahead stock return on the current stock return interacted not only with day-of-the-week dummies but also with volume. Alternatively, we interact the current return with dummies and with estimated conditional variance. Finally, we report a regression in which the current return is interacted with dummies, conditional variance, volume, and volume squared. The last of these variables is included to capture any nonlinearity that may exist in the relation between volume and autocorrelation.

Panel A of Table II uses the sample period 1962-1987. Over this period Table I showed that 5.7 percent of the variance of the one-day-ahead value-weighted index return can be explained by a 
TABLE II

VOlume, Volatility, AND THE FIRST AUTOCORRELATION $r_{t+1}=\alpha+\left(\sum_{i=1}^{5} \beta_{i} D_{i}+\gamma_{1} V_{t}+\gamma_{2} V_{t}^{2}+\gamma_{3}\left(1000 \sigma_{t}^{2}\right)\right) r_{t}$

\begin{tabular}{|c|c|c|c|c|}
\hline $\begin{array}{l}\text { Sample period } \\
\text { and specification }\end{array}$ & $\begin{array}{c}\gamma_{1} \\
\text { (s.e.) }\end{array}$ & $\begin{array}{c}\gamma_{2} \\
\text { (s.e.) }\end{array}$ & $\begin{array}{c}\gamma_{3} \\
\text { (s.e.) }\end{array}$ & $R^{2}$ \\
\hline \multicolumn{5}{|l|}{ A: $7 / 3 / 62-9 / 30 / 87$} \\
\hline Volume & $\begin{array}{c}-0.328 \\
(0.060)\end{array}$ & & & 0.065 \\
\hline Volatility & & & $\begin{array}{c}-0.047 \\
(0.241)\end{array}$ & 0.057 \\
\hline Volume and volatility & $\begin{array}{c}-0.427 \\
(0.077)\end{array}$ & $\begin{array}{c}0.265 \\
(0.140)\end{array}$ & $\begin{array}{c}0.055 \\
(0.248)\end{array}$ & 0.066 \\
\hline \multicolumn{5}{|l|}{ B: $7 / 3 / 62-12 / 31 / 74$} \\
\hline Volume & $\begin{array}{c}-0.445 \\
(0.114)\end{array}$ & & & 0.095 \\
\hline Volatility & & & $\begin{array}{c}-0.058 \\
(0.283)\end{array}$ & 0.084 \\
\hline Volume and volatility & $\begin{array}{c}-0.546 \\
(0.112)\end{array}$ & $\begin{array}{c}0.511 \\
(0.259)\end{array}$ & $\begin{array}{c}0.112 \\
(0.290)\end{array}$ & 0.097 \\
\hline \multicolumn{5}{|l|}{$\mathrm{C}: 1 / 2 / 75-9 / 30 / 87$} \\
\hline Volume & $\begin{array}{c}-0.214 \\
(0.073)\end{array}$ & & & 0.046 \\
\hline Volatility & & & $\begin{array}{c}-0.879 \\
(0.392)\end{array}$ & 0.045 \\
\hline Volume and volatility & $\begin{array}{c}-0.212 \\
(0.110)\end{array}$ & $\begin{array}{c}0.056 \\
(0.179)\end{array}$ & $\begin{array}{c}-0.661 \\
(0.391)\end{array}$ & 0.047 \\
\hline \multicolumn{5}{|l|}{ D: $7 / 3 / 62-12 / 30 / 88$} \\
\hline Volume & $\begin{array}{c}-0.169 \\
(0.080)\end{array}$ & & & 0.062 \\
\hline Volatility & & & $\begin{array}{c}-0.068 \\
(0.106)\end{array}$ & 0.059 \\
\hline Volume and volatility & $\begin{array}{c}-0.290 \\
(0.148)\end{array}$ & $\begin{array}{c}0.173 \\
(0.116)\end{array}$ & $\begin{array}{c}-0.025 \\
(0.105)\end{array}$ & 0.064 \\
\hline
\end{tabular}

regression on current return interacted with day-of-the-week dummies. The first row of panel A shows that this $R^{2}$ statistic can be increased to 6.5 percentage points by interacting the regressor with dummies and detrended trading volume. The coefficient on the product of volume and the stock return is -0.33 with a heteroskedasticity-consistent standard error of 0.06 . This is economically as well as statistically significant. The standard deviation of detrended volume is about 0.25 . Thus, as volume moves from two standard deviations below the mean to two standard deviations above, the first-order autocorrelation of the stock return is reduced by about 0.3 . 
These strong results for volume are not matched by our volatility measure. When volume is excluded from the regression, volatility enters negatively, but it is statistically and economically insignificant. When volume and volume squared appear in the regression, volatility enters positively but is again insignificant. The quadratic term on volume is positive and not quite significant at the 5 percent level. Thus, in panel A there is only weak evidence for any specification more complicated than the linear volume regression reported in the second row.

In panels B and C of Table II, we break the $1962-1987$ period into subsamples 1962-1974 and 1975-1987. The strongest results come from the earlier subsample 1962-1974. In this period the average first-order autocorrelation of the stock return is almost 0.3 , and a regression of the one-day-ahead return on the current return interacted with day-of-the-week dummies gives an $R^{2}$ statistic of 8.4 percent. This can be increased by more than a percentage point by taking account of a linear relationship between the autocorrelation and trading volume. Once again volatility and quadratic volume terms add little. In the later subsample, 19751987 , the first-order autocorrelation is much smaller on average. Volume raises the regression $R^{2}$ from 4.3 percent only to 4.6 percent, although the linear volume term is still statistically significant with a $t$-statistic of 2.9. In this period there is a stronger negative relationship between volatility and autocorrelation, although volume is still slightly superior to volatility when both are included in the regression.

Finally, in panel D of Table II we ask whether the addition of the stock market crash period to the sample weakens or reinforces our results. It turns out that the most recent data weaken the effect of volume on the first-order autocorrelation of returns. Even in the 1962-1988 period, however, volume remains significant at the 5 percent level. We note also that the $1962-1988$ period is the only one for which day-of-the-week dummies make a major difference to the results. When these dummies are excluded, the volume effect becomes much stronger in the 1962-1988 period than in the 1962-1987 period. This is because the stock price reversals of the week of October 19, 1987, are captured by day-of-the-week dummies when these are included, or by volume when dummies are omitted.

Table III has exactly the same structure as Table I, but now the dependent variable is the two-day-ahead stock return so the table describes the second-order autocorrelation of the return. The 
TABLE III

The Second Autocorrelation of S'Tock Returns

(2)

$$
\begin{gathered}
r_{t+2}=\alpha+\beta r_{t} \\
r_{t+2}=\alpha+\left(\Sigma_{i=1}^{5} \beta_{i} D_{i}\right) r_{t}
\end{gathered}
$$

\begin{tabular}{lccc}
\hline \hline & $\beta$ & & \\
Sample period & $($ s.e. $)$ & $R^{2}(1)$ & $R^{2}(2)$ \\
\hline A: $7 / 3 / 62-9 / 30 / 87$ & 0.016 & 0.000 & 0.004 \\
& $(0.017)$ & & \\
B: $7 / 3 / 62-12 / 31 / 74$ & 0.017 & 0.000 & 0.009 \\
C: $1 / 2 / 75-9 / 30 / 87$ & $(0.030)$ & & 0.002 \\
D: $7 / 3 / 62-12 / 30 / 88$ & 0.013 & 0.000 & 0.012 \\
& $(0.019)$ & & \\
\hline \hline
\end{tabular}

average second-order autocorrelation is small and statistically insignificant in every sample period. Even when day-of-the-week dummies are interacted with the current return, the $R^{2}$ statistic of the regression is less than 1.5 percent.

Table IV, which has the same structure as Table II, shows some evidence for volume effects on the second autocorrelation. However, the evidence is much weaker than that for volume effects on the first autocorrelation. Over the 1962-1987 sample period (panel A) we find that volume enters the regression significantly only when it is included in quadratic form. The linear coefficient is -0.23 with a standard error of 0.08 , while the quadratic coefficient is 0.55 with a standard error of 0.15 . These coefficients imply that the second-order autocorrelation falls with volume until volume reaches 0.2 , about two-thirds of a standard deviation above its mean. At higher levels of volume the positive quadratic term dominates, and the autocorrelation starts to increase again. Looking at subsamples in panels $\mathrm{B}$ and $\mathrm{C}$, we find that the evidence for volume effects on the second autocorrelation comes entirely from the 1962-1974 period. Finally, in panel D we see that the addition of the stock market crash period leads to stronger evidence for a volume effect on the second autocorrelation.

One might ask whether higher-order autocorrelations also change with trading volume. As a crude way to answer this question without having to look at each autocorrelation individu- 
TABLE IV

Volume, Volatility, AND THE SECOND AUTOCORRELATION $r_{t+2}=\alpha+\left(\Sigma_{i=1}^{5} \beta_{i} D_{i}+\gamma_{1} V_{t}+\gamma_{2} V_{t}^{2}+\gamma_{3}\left(1000 \sigma_{t}^{2}\right)\right) r_{t}$

\begin{tabular}{|c|c|c|c|c|}
\hline $\begin{array}{c}\text { Sample period } \\
\text { and specification }\end{array}$ & $\begin{array}{c}\gamma_{1} \\
\text { (s.e.) }\end{array}$ & $\begin{array}{c}\gamma_{2} \\
\text { (s.e.) }\end{array}$ & $\begin{array}{c}\gamma_{3} \\
\text { (s.e.) }\end{array}$ & $R^{2}$ \\
\hline \multicolumn{5}{|l|}{ A: $7 / 3 / 62-9 / 30 / 87$} \\
\hline Volume & $\begin{array}{c}-0.028 \\
(0.060)\end{array}$ & & & 0.004 \\
\hline Volatility & & & $\begin{array}{c}0.086 \\
(0.276)\end{array}$ & 0.004 \\
\hline Volume and volatility & $\begin{array}{c}-0.233 \\
(0.079)\end{array}$ & $\begin{array}{c}0.550 \\
(0.146)\end{array}$ & $\begin{array}{c}0.071 \\
(0.276)\end{array}$ & 0.008 \\
\hline \multicolumn{5}{|l|}{ B: $7 / 3 / 62-12 / 31 / 74$} \\
\hline Volume & $\begin{array}{c}-0.186 \\
(0.115)\end{array}$ & & & 0.011 \\
\hline Volatility & & & $\begin{array}{c}-0.012 \\
(0.338)\end{array}$ & 0.009 \\
\hline Volume and volatility & $\begin{array}{c}-0.390 \\
(0.113)\end{array}$ & $\begin{array}{c}1.149 \\
(0.345)\end{array}$ & $\begin{array}{c}-0.039 \\
(0.326)\end{array}$ & 0.021 \\
\hline \multicolumn{5}{|l|}{ C: $1 / 2 / 75-9 / 30 / 87$} \\
\hline Volume & $\begin{array}{c}0.074 \\
(0.069)\end{array}$ & & & 0.003 \\
\hline Volatility & & & $\begin{array}{c}0.613 \\
(0.391)\end{array}$ & 0.003 \\
\hline Volume and volatility & $\begin{array}{c}-0.015 \\
(0.109)\end{array}$ & $\begin{array}{c}0.138 \\
(0.175)\end{array}$ & $\begin{array}{c}0.500 \\
(0.400)\end{array}$ & 0.004 \\
\hline \multicolumn{5}{|l|}{ D: $7 / 3 / 62-12 / 30 / 88$} \\
\hline Volume & $\begin{array}{c}-0.178 \\
(0.089)\end{array}$ & & & 0.016 \\
\hline Volatility & & & $\begin{array}{c}0.007 \\
(0.105)\end{array}$ & 0.011 \\
\hline Volume and volatility & $\begin{array}{c}-0.024 \\
(0.087)\end{array}$ & $\begin{array}{c}-0.241 \\
(0.119)\end{array}$ & $\begin{array}{c}0.072 \\
(0.102)\end{array}$ & 0.019 \\
\hline
\end{tabular}

ally, we have run regressions of stock returns on moving averages of past stock returns and on moving averages of past stock returns interacted with trading volume. Regressions of this sort (where the lags in the moving averages run from 1 to 5 or from 2 to 6 ) yield results similar to those reported in Tables II and IV, with somewhat reduced statistical significance. This suggests that the main volume effects are in the first couple of autocorrelations, but that there are at least no offsetting effects in higher autocorrelations out to lags 5 or 6 . 
TABLE V

Volume, Volatility, AND the First AUtOCORRELATION:

ALternative Volume MEasures

$r_{t+1}=\alpha+\left(\sum_{i=1}^{5} \beta_{i} D_{i}+\gamma_{1} V_{t}+\gamma_{2} M A V_{t}+\gamma_{3}\left(V_{t}+M A V_{t}\right)\right) r_{t}$

\begin{tabular}{|c|c|c|c|c|}
\hline $\begin{array}{l}\text { Sample period and } \\
\text { specification }\end{array}$ & $\begin{array}{c}\gamma_{1} \\
\text { (s.e.) }\end{array}$ & $\begin{array}{c}\gamma_{2} \\
\text { (s.e.) }\end{array}$ & $\begin{array}{c}\gamma_{3} \\
\text { (s.e.) }\end{array}$ & $R^{2}$ \\
\hline \multicolumn{5}{|l|}{ A: $7 / 3 / 62-9 / 30 / 87$} \\
\hline Detrended volume & $\begin{array}{c}-0.328 \\
(0.060)\end{array}$ & & & 0.065 \\
\hline Total volume & & & $\begin{array}{c}-0.156 \\
(0.028)\end{array}$ & 0.064 \\
\hline $\begin{array}{l}\text { Detrended and } \\
\text { trend volume }\end{array}$ & $\begin{array}{c}-0.313 \\
(0.061)\end{array}$ & $\begin{array}{r}-0.090 \\
(0.037)\end{array}$ & & 0.066 \\
\hline \multicolumn{5}{|l|}{ B: $7 / 3 / 62-12 / 31 / 74$} \\
\hline Detrended volume & $\begin{array}{c}-0.445 \\
(0.114)\end{array}$ & & & 0.095 \\
\hline Total volume & & & $\begin{array}{c}-0.227 \\
(0.081)\end{array}$ & 0.087 \\
\hline $\begin{array}{l}\text { Detrended and } \\
\text { trend volume }\end{array}$ & $\begin{array}{c}-0.417 \\
(0.108)\end{array}$ & $\begin{array}{c}0.292 \\
(0.141)\end{array}$ & & 0.097 \\
\hline \multicolumn{5}{|l|}{ C: $1 / 2 / 75-9 / 30 / 87$} \\
\hline Detrended volume & $\begin{array}{c}-0.214 \\
(0.073)\end{array}$ & & & 0.046 \\
\hline Total volume & & & $\begin{array}{c}-0.132 \\
(0.040)\end{array}$ & 0.047 \\
\hline $\begin{array}{l}\text { Detrended and } \\
\text { trend volume }\end{array}$ & $\begin{array}{c}-0.218 \\
(0.073)\end{array}$ & $\begin{array}{c}-0.090 \\
(0.046)\end{array}$ & & 0.047 \\
\hline \multicolumn{5}{|l|}{ D: $7 / 3 / 62-12 / 30 / 88$} \\
\hline Detrended volume & $\begin{array}{c}-0.169 \\
(0.080)\end{array}$ & & & 0.062 \\
\hline Total volume & & & $\begin{array}{c}-0.091 \\
(0.050)\end{array}$ & 0.063 \\
\hline $\begin{array}{l}\text { Detrended and } \\
\text { trend volume }\end{array}$ & $\begin{array}{c}-0.134 \\
(0.066)\end{array}$ & $\begin{array}{r}-0.065 \\
(0.059)\end{array}$ & & 0.064 \\
\hline
\end{tabular}

\section{Alternative Volume and Volatility Measures}

So far we have worked exclusively with detrended volume. It is natural to ask whether similar results could be achieved without detrending. To answer this, in Table $\mathrm{V}$ we run similar regressions to those in Table II, but using total volume instead of detrended volume. We also run regressions including both the detrended series and the trend. The general pattern is that detrended volume has superior explanatory power to total volume, although this is not true in 1975-1987. When both detrended and trend volume are 
included, the coefficient on detrended volume is always negative and significant, whereas the coefficient on the trend switches sign from positive in 1962-1974 to negative in 1975-1987.

In an earlier version of this paper, we also used an unobserved components model to stochastically detrend volume. The resulting series was much less persistent than the detrended series used here, having a positive first-order autocorrelation and than a series of negative higher-order autocorrelations. The stochastically detrended volume series gave results similar to but systematically weaker than those in Table II. ${ }^{5}$ This can be interpreted in terms of our theoretical expectation that the serial correlation of stock returns declines when volume increases relative to the ability of market makers to absorb volume. A one-year backward moving average of past volume, which reacts sluggishly to changes in volume, seems to be a better measure of market making capacity than an estimated random walk component from an unobserved components model, which reacts very quickly to changes in volume. ${ }^{6}$

To check the robustness of this finding, we have also tried measuring volume as the deviations of log turnover from threemonth and five-year backward moving averages. Both these alternative moving average measures gave results similar to those reported in Table II. Thus, it seems to be important to measure volume relative to a slowly adjusting trend, but the exact details of trend construction are not crucial.

The results reported above also use a single measure of volatility, the fitted value from a QGARCH model. The choice of this particular model in the GARCH class is not critical since all models in this class give very similar fitted variances. Nelson [1992] shows that high-frequency data can be used to estimate variance very precisely, even when variance is changing through time and the true model for variance is unknown.

It could be objected, however, that estimated conditional volatility cannot compete equally with trading volume because each day's conditional variance uses information only through the

5. LeBaron [1992b] builds on the work of this paper to explore the relation between autocorrelation and high-frequency volume movements more thoroughly.

6. Grossman and Miller [1988] model the long-run determination of marketmaking capacity and show that in steady state the constant negative autocorrelation of stock price changes is determined by the cost of maintaining a market presence and the risk aversion of market makers. We believe that market-making capacity adjusts slowly to the steady state, and this is consistent with our empirical results. For simplicity, our theoretical model assumes that market-making capacity is fixed; it is a short-run counterpart to Grossman and Miller's long-run model. 
TABLE VI

The First Autocorrelation of Stock Returns: Alternative Sample Perions

$$
\begin{gathered}
r_{t+1}=\alpha+\beta r_{t} \\
r_{t+1}=\alpha+\left(\sum_{i=1}^{5} \beta_{i} D_{i}\right) r_{t}
\end{gathered}
$$

\begin{tabular}{lccc}
\hline \hline & $\beta$ & & \\
Sample period & $($ s.e. $)$ & $R^{2}(1)$ & $R^{2}(2)$ \\
\hline E: $1 / 2 / 26-6 / 29 / 62$ & 0.039 & 0.002 & 0.005 \\
F: $1 / 2 / 26-12 / 30 / 39$ & $(0.023)$ & & 0.004 \\
G: $1 / 2 / 40-12 / 31 / 49$ & 0.015 & 0.000 & 0.018 \\
H: $1 / 3 / 50-6 / 29 / 62$ & 0.112 & 0.012 & 0.037 \\
I: $1 / 2 / 26-9 / 30 / 87$ & $(0.034)$ & & 0.017 \\
& 0.130 & & 0.008 \\
\hline \hline
\end{tabular}

previous day. A simple way to respond to this is to add the current squared return to the regression, since in any GARCH model the squared return is the innovation in conditional variance. When we do this, we find that the current squared return sometimes enters significantly but does not have any important effect on the estimated volume effect. To save space, we do not report results for this specification.

\section{Evidence from Earlier Periods}

As a further check on the robustness of our results, in Tables VI and VII we look at Schwert's [1989] daily stock index return over the period from 1926. The tables use five different samples: the full pre-1962 data set 1/2/26-6/29/62 (sample E); decadal subsamples $1 / 2 / 26-12 / 30 / 39,1 / 2 / 40-12 / 31 / 49$, and $1 / 3 / 50-6 / 29 / 62$ (samples $\mathrm{F}, \mathrm{G}$, and $\mathrm{H}$, respectively); and a long sample splicing together Schwert's series with the CRSP valueweighted index over the period $1 / 2 / 26-9 / 30 / 87$ (sample I). ${ }^{7}$

Table VI shows that the average first autocorrelation of stock returns has varied considerably over the decades. In the 1930 s it was very small at 0.015 , but it increased to above 0.1 in the $1940 \mathrm{~s}$ and 1950s. Table VII shows that the effect of volume on autocorre-

7. Sample $I$ is long enough that adding the stock market crash period has very little effect on the results, so to save space we do not report results for 1/2/26-12/30/88. 
TABLE VII

Volume, Volatility, and the First Autocorrelation:

Alternative Sample Perions

$$
r_{i+1}=\alpha+\left(\Sigma_{i=1}^{5} \beta_{i} D_{i}+\gamma_{1} V_{t}+\gamma_{t}+\gamma_{3}\left(1000 \mathrm{o}_{r}^{2}\right)\right) r_{t}
$$

\begin{tabular}{|c|c|c|c|c|}
\hline $\begin{array}{l}\text { Sample period and } \\
\text { specification }\end{array}$ & $\begin{array}{c}\gamma_{1} \\
\text { (s.e.) }\end{array}$ & $\begin{array}{c}\gamma_{2} \\
\text { (s.e.) }\end{array}$ & $\begin{array}{c}\gamma_{3} \\
\text { (s.e.) }\end{array}$ & $R^{2}$ \\
\hline \multicolumn{5}{|l|}{$\mathrm{E}: 1 / 2 / 26-6 / 29 / 62$} \\
\hline Volume & $\begin{array}{c}0.053 \\
(0.045)\end{array}$ & & 0.006 & \\
\hline Volatility & & & $\begin{array}{c}-0.002 \\
(0.041)\end{array}$ & 0.005 \\
\hline Volume and volatility & $\begin{array}{c}-0.114 \\
(0.039)\end{array}$ & $\begin{array}{c}0.064 \\
(0.051)\end{array}$ & $\begin{array}{c}0.009 \\
(0.043)\end{array}$ & \\
\hline \multicolumn{5}{|l|}{$\mathrm{F}: 1 / 2 / 26-12 / 30 / 39$} \\
\hline Volume & $\begin{array}{c}-0.038 \\
(0.053)\end{array}$ & & & 0.004 \\
\hline Volatility & & & $\begin{array}{c}0.027 \\
(0.044)\end{array}$ & 0.004 \\
\hline Volume and volatility & $\begin{array}{c}-0.131 \\
(0.047)\end{array}$ & $\begin{array}{c}0.079 \\
(0.058)\end{array}$ & $\begin{array}{c}0.042 \\
(0.046)\end{array}$ & 0.007 \\
\hline \multicolumn{5}{|l|}{ G: $1 / 2 / 40-12 / 31 / 49$} \\
\hline Volume & $\begin{array}{c}-0.097 \\
(0.061)\end{array}$ & & & 0.021 \\
\hline Volatility & & & $\begin{array}{c}-0.173 \\
(0.114)\end{array}$ & 0.021 \\
\hline Volume and volatility & $\begin{array}{r}-0.104 \\
(0.062)\end{array}$ & $\begin{array}{c}0.046 \\
(0.064)\end{array}$ & $\begin{array}{r}-0.130 \\
(0.145)\end{array}$ & 0.022 \\
\hline \multicolumn{5}{|l|}{$H: 1 / 3 / 50-6 / 29 / 62$} \\
\hline Volume & $\begin{array}{c}-0.174 \\
(0.099)\end{array}$ & & & 0.042 \\
\hline Volatility & & & $\begin{array}{c}-0.420 \\
(0.199)\end{array}$ & 0.044 \\
\hline Volume and volatility & $\begin{array}{c}-0.152 \\
(0.094)\end{array}$ & $\begin{array}{c}0.216 \\
(0.175)\end{array}$ & $\begin{array}{c}-0.492 \\
(0.244)\end{array}$ & 0.046 \\
\hline \multicolumn{5}{|l|}{ I: $1 / 2 / 26-9 / 30 / 87$} \\
\hline Volume & $\begin{array}{c}-0.085 \\
(0.043)\end{array}$ & & & 0.011 \\
\hline Volatility & & & $\begin{array}{c}-0.029 \\
(0.040)\end{array}$ & 0.009 \\
\hline Volume and volatility & $\begin{array}{r}-0.119 \\
(0.039)\end{array}$ & $\begin{array}{c}0.050 \\
(0.049)\end{array}$ & $\begin{array}{c}-0.014 \\
(0.041)\end{array}$ & 0.011 \\
\hline
\end{tabular}




\section{TABLE VIII}

The First Autocorrelation of Stock Returns:

The Dow Jones Industrial Average

(1) $r_{t+1}=\alpha+\beta r_{t}$

(2) $r_{t+1}=\alpha+\left(\Sigma_{\mathrm{i}=1}^{5} \beta_{i} D_{i}\right) r_{t}$

\begin{tabular}{lccc}
\hline \hline Sample period & $\beta$ & & \\
\hline A: $7 / 3 / 62-9 / 30 / 87$ & $($ s.e. $)$ & $R^{2}(1)$ & $R^{2}(2)$ \\
\hline B: $7 / 3 / 62-12 / 31 / 74$ & 0.141 & 0.020 & 0.027 \\
& $(0.016)$ & & \\
C: $1 / 2 / 75-9 / 30 / 87$ & 0.210 & 0.044 & 0.046 \\
D: $7 / 3 / 62-12 / 30 / 88$ & $(0.026)$ & & 0.023 \\
& 0.087 & 0.008 & 0.034 \\
\hline
\end{tabular}

lation has always been negative, although in many sample periods it is statistically significant only when squared volume and volatility are also included in the regression. ${ }^{8}$ Volatility is statistically significant only in the period 1950-1962.

\section{E. Nonsynchronous Trading}

All the empirical results so far have used the return on a value-weighted stock index. It could be objected that the serial correlation of the index return is mismeasured because the individual stocks in the index are not all traded exactly at the close. In principle, nonsynchronous trading can lead to spurious positive autocorrelation in an index return, although Lo and MacKinlay [1990] have shown that this effect is very small unless stocks fail to trade for implausibly long periods of time.

As one way to respond to this objection, in Tables VIII and IX we repeat our basic regressions lising price changes of the Dow Jones Industrial Average. Although this series omits dividends, this has only a minimal effect on daily autocorrelations. Nonsynchronous trading should also have only a trivial effect on the behavior of the Dow Jones. The average autocorrelation of the Dow Jones is much smaller than the average autocorrelation of the

8. An anonymous referee has objected that we report results with squared volume only because they are statistically significant. We note, however, that we reported the same squared volume regressions in the first version of this paper which did not look at the older data. 


\section{TABLE IX}

Volume, Volatility, aNd the First Autocorrelation:

The Dow Jones Industrial Average

$$
r_{t+1}=\alpha+\left(\Sigma_{i=1}^{5} \beta_{i} D_{i}+\gamma_{1} V_{t}+\gamma_{2} V_{t}^{2}+\gamma_{3}\left(1000 \sigma_{t}^{2}\right)\right) r_{t}
$$

\begin{tabular}{|c|c|c|c|c|}
\hline $\begin{array}{c}\text { Sample period } \\
\text { and specification }\end{array}$ & $\begin{array}{c}\gamma_{1} \\
\text { (s.e.) }\end{array}$ & $\begin{array}{c}\gamma_{2} \\
\text { (s.e.) }\end{array}$ & $\begin{array}{c}\gamma_{3} \\
\text { (s.e.) }\end{array}$ & $R^{2}$ \\
\hline \multicolumn{5}{|l|}{ A: $7 / 3 / 62-9 / 30 / 87$} \\
\hline Volume & $\begin{array}{c}-0.257 \\
(0.061)\end{array}$ & & & 0.032 \\
\hline Volatility & & & $\begin{array}{c}-0.142 \\
(0.263)\end{array}$ & 0.027 \\
\hline Volume and volatility & $\begin{array}{c}-0.358 \\
(0.074)\end{array}$ & $\begin{array}{c}0.278 \\
(0.147)\end{array}$ & $\begin{array}{c}0.080 \\
(0.268)\end{array}$ & 0.033 \\
\hline \multicolumn{5}{|l|}{ B: $7 / 3 / 62-12 / 31 / 74$} \\
\hline Volume & $\begin{array}{c}-0.359 \\
(0.116)\end{array}$ & & & 0.053 \\
\hline Volatility & & & $\begin{array}{c}-0.128 \\
(0.304)\end{array}$ & 0.046 \\
\hline Volume and volatility & $\begin{array}{c}-0.450 \\
(0.112)\end{array}$ & $\begin{array}{c}0.498 \\
(0.276)\end{array}$ & $\begin{array}{c}0.023 \\
(0.308)\end{array}$ & 0.055 \\
\hline \multicolumn{5}{|l|}{ C: $1 / 2 / 75-9 / 30 / 87$} \\
\hline Volume & $\begin{array}{c}-0.157 \\
(0.073)\end{array}$ & & & 0.025 \\
\hline Volatility & & & $\begin{array}{c}-1.138 \\
(0.380)\end{array}$ & 0.026 \\
\hline Volume and volatility & $\begin{array}{c}-0.177 \\
(0.102)\end{array}$ & $\begin{array}{c}0.138 \\
(0.174)\end{array}$ & $\begin{array}{c}-1.036 \\
(0.372)\end{array}$ & 0.027 \\
\hline \multicolumn{5}{|l|}{ D: $7 / 3 / 62-12 / 30 / 88$} \\
\hline Volume & $\begin{array}{c}-0.127 \\
(0.094)\end{array}$ & & & 0.037 \\
\hline Volatility & & & $\begin{array}{c}0.037 \\
(0.134)\end{array}$ & 0.034 \\
\hline Volume and volatility & $\begin{array}{c}-0.251 \\
(0.159)\end{array}$ & $\begin{array}{c}0.103 \\
(0.142)\end{array}$ & $\begin{array}{c}0.081 \\
(0.132)\end{array}$ & 0.039 \\
\hline
\end{tabular}

value-weighted portfolio, only one-half as large in some periods. However, there is still a highly significant estimated effect of volume on the autocorrelation.

Another way to respond to the nonsynchronous trading concern is to use data on individual stock returns. Nonsynchronous trading creates spurious positive autocorrelation in an index return because today's market return is measured contemporaneously for those stocks that trade today, but only with a lag for nontraded stocks. However, nonsynchronous trading has only a trivial effect on measured individual stock return autocorrelations [Lo and MacKinlay, 1990]. Even when one uses individual stock 
TABLE X

Volume and the First Autocorrelation: Individual Stock Returns Equal-weighted index regression:

$$
r_{E W, t+1}=\alpha_{E W}+\left(\Sigma_{i=1}^{5} \beta_{E W, i} D_{i}+\gamma_{E W} V_{t}\right) r_{E W, t}
$$

Pooled regression:

$$
r_{j, t+1}+\alpha_{P}+\left(\Sigma_{i=1}^{5} \beta_{P, i} D_{i}+\gamma_{P} V_{t}\right) r_{j, t}, \quad j=1, \ldots, 32
$$

Individual stock regressions:

$$
\begin{gathered}
r_{j, t+1}=\alpha_{j}+\left(\Sigma_{i=1}^{5} \beta_{j, i} D_{i}+\gamma_{j} V_{t}\right) r_{j, t}, \quad j=1, \ldots, 32 \\
\bar{\gamma}=(1 / 32) \Sigma_{j=1}^{32} \gamma_{j}, \quad \bar{t}_{\gamma}=(1 / 32) \Sigma_{j=1}^{32} t_{\gamma j}
\end{gathered}
$$

\begin{tabular}{lcccc}
\hline \hline Sample period & $\begin{array}{c}\gamma_{E W} \\
(\mathrm{s.e.})\end{array}$ & $\begin{array}{c}\gamma_{p} \\
(\mathrm{s.e.})\end{array}$ & $\begin{array}{c}\bar{\gamma} \\
(\#<0)\end{array}$ & $\begin{array}{c}\bar{t}_{\gamma} \\
(\#<-1.64)\end{array}$ \\
\hline A: $7 / 3 / 62-9 / 30 / 87$ & -0.311 & -0.093 & -0.092 & -1.368 \\
& $(0.064)$ & $(0.028)$ & $(31)$ & $(12)$ \\
B: $7 / 3 / 62-12 / 31 / 74$ & -0.469 & -0.125 & -0.122 & -1.104 \\
& $(0.127)$ & $(0.049)$ & $(30)$ & $(11)$ \\
C: $1 / 2 / 75-9 / 30 / 87$ & -0.160 & -0.062 & -0.059 & -0.719 \\
& $(0.074)$ & $(0.034)$ & $(25)$ & $(6)$ \\
D: $7 / 3 / 62-12 / 30 / 88$ & -0.173 & -0.121 & -0.108 & -1.087 \\
& $(0.116)$ & $(0.083)$ & $(31)$ & $(5)$ \\
\hline \hline
\end{tabular}

returns, aggregate volume is probably a better variable than individual volume because idiosyncratic buying or selling pressure does not create systematic risk for market makers. Accordingly, we combine individual stock returns with the single aggregate volume series.

Table X summarizes results for 32 large stocks that were traded throughout the period 1962-1988 and were among the 100 largest at both the beginning and end of the period. The first column of the table reports the volume effect on the autocorrelation of an equally weighted index of these stocks. The index is very similar to the Dow Jones, having an almost identical first autocorrelation and a correlation with the Dow Jones of about 0.95 . Not surprisingly, therefore, the effect of volume on the index autocorrelation is similar to the effect reported in Table IX. The second column of Table $\mathrm{X}$ shows the volume effect on the correlation of each stock return with its own first lag, where the individual returns are stacked together in a single pooled regression. The standard error is corrected for heteroskedasticity and for the contemporaneous correlation of individual stock returns, using the method of White [1984]. The volume effect on the own autocorrela- 
tion of each stock return is smaller than the volume effect on the index return, but the statistical significance of the effect is not much reduced.

The third column of Table $X$ shows the average effect of volume on the first autocorrelation across 32 separate OLS regressions, one for each individual stock. Not surprisingly the crosssectional average effect is close to the effect in the pooled regression. The number of negative individual coefficients is also reported; at least 25 of these coefficients are negative in every sample period. Finally, the fourth column of Table $X$ shows the cross-sectional average $t$-statistic for the effect of volume on the autocorrelation, and the number of individual $t$-statistics that are less than -1.64 (the 5 percent level for a one-tailed test, or the 10 percent level for a two-tailed test). The cross-sectional average $t$-statistic is less than -1 in every period except 1975-1987, and as many as a third of the individual $t$-statistics are less than -1.64 .

We interpret these results as strong evidence that nonsynchronous trading is not solely responsible for the phenomena we have described.

\section{Volume AND Stock Returns: A Theoretical Model}

In this section we present a model of noninformational trading that can account for the empirical relationship between trading volume and the serial correlation of stock returns. Several authors, including Campbell and Kyle [1993], De Long, Shleifer, Summers, and Waldmann [1989, 1990], Grossman and Miller [1988], and Shiller [1984], have developed models in which expected stock returns vary through time as some investors accommodate the shifting stock demands of other investors. But none of these authors explicitly work out the implications of their models for trading volume.

Most previous work has modeled noninformational trading as an exogenous process. De Long, Shleifer, Summers, and Waldmann $[1989,1990]$ derive noninformational trading from shifting misperceptions of future stock payoffs. Here we derive noninformational trading from shifts in the risk aversion of some traders. We do this because we find it natural to relate changing demands to changing tastes, ${ }^{9}$ but the basic intuition of our model carries through

9. For simplicity, we treat shifts in investors' risk aversion as exogenous. More generally, investors' attitudes toward risk may depend on wealth and other state variables. This can lead them to follow dynamic hedging strategies even when they face a constant investment opportunity set [Grossman and Zhou, 1992]. 
regardless of how noninformational trading is introduced. Any such trading will give the same qualitative relation between volume and the serial correlation of returns.

We consider an economy in which there exist two assets: a risk-free asset and a risky asset ("stock"). We assume that innovations in the stock price are driven by three random variables: (i) the innovation to the current dividend, (ii) the innovation to information about future dividends, and (iii) the innovation to the time-varying risk aversion of a subset of investors. Shock (i) causes the payoff to the stock to be stochastic so that a premium is demanded by investors for holding it. Shock (iii) generates changes in the market's aggregate risk aversion, which cause the expected return on the stock to vary. Shock (ii) is in the model so that prices and dividends do not fully reveal the state of the economy and volume provides additional information.

The properties of our model can be understood as follows. If a large subset of investors becomes more risk averse, and the rest of the economy does not change its attitudes toward risk, then the marginal investor is more risk averse, and in equilibrium, the expected return from holding the stock must rise to compensate the marginal investor for bearing the risk. Simultaneously, risk is reallocated from those people who become more risk averse to the rest of the market. The reallocation is observed as a rise in trading volume. Note that the rise in expected future returns is brought about by a fall in the current stock price that causes a negative current return. Therefore, a large trading volume will be associated with a relatively large negative autocorrelation of returns.

\section{A. The Economy}

Our model further specifies the economy as follows. The risk-free asset, which is in elastic supply, guarantees a rate of return $R=1+r$ with $r>0$. We assume that there is a fixed supply of stock shares per capita, which is normalized to 1 . Shares are traded in a competitive market. Each share pays a dividend in period $t$ of $D_{t}=\bar{D}+\tilde{D}_{t} \cdot \bar{D}>0$ is the mean dividend, while $\tilde{D}_{t}$ is the zero-mean stochastic component of the dividend. (We use similar notational conventions for other variables below.) $\bar{D}_{t}$ follows the process:

$$
\tilde{D}_{t}=\alpha_{D} \tilde{D}_{t-1}+u_{D, t}, \quad 0 \leq \alpha_{D} \leq 1 .
$$

We assume that the innovation $u_{D, t}$ is i.i.d. with normal distribution $u_{D, t} \sim \mathscr{N}\left(0, \sigma_{u}^{2}\right)$. 
There are two types of investors in the economy, type A and type B. Both types of investors have constant absolute risk aversion. The type A investors' risk aversion parameter is a constant $a$, while the type B investors' risk aversion parameter is $b_{t}$, which may change over time. Let $\omega$ be the fraction of type A investors.

Each period, investors solve the following problem:

$$
\max _{X} E_{t}\left[-\exp \left(-\Psi W_{t+1}\right)\right], \quad \Psi=a, b_{t},
$$

subject to

$$
W_{t+1}=W_{t} R+X_{t}\left(P_{t+1}+D_{t+1}-R P_{t}\right)
$$

where $W_{t}$ is wealth, $X_{t}$ is the holding of the risky asset, and $P_{t}$ is the ex dividend share price of the stock, all measured at time $t . E_{t}$ is the expectation operator conditioned on investors' information set $\mathscr{I}_{t}$ at time $t$.

The set $\mathscr{I}_{t}$ contains the stock price $P_{t}$ and the dividend $D_{t}$. It also contains a signal, $S_{t}$, which all investors receive at time $t$ about the future dividend shock $u_{D, t+1}$ :

$$
u_{D, t+1}=S_{t}+\epsilon_{D, t+1} \text {. }
$$

For simplicity, we assume that $S_{t}$ and $\epsilon_{D, t+1}$ are jointly i.i.d. normal, $E\left[u_{D, t+1} \mid S_{t}\right]=S_{t}, \epsilon_{D, t} \sim \mathscr{N}\left(0, \sigma_{\epsilon}^{2}\right)$, and $S_{t} \sim \mathscr{N}\left(0, \sigma_{S}^{2}\right)$.

\section{B. The Equilibrium Price of the Risky Asset}

Let $F_{t}$ (the "cum-dividend fundamental value" of the stock) be the present value of the expected future cash flow from a share of the stock, including today's dividend, discounted at the risk-free rate. It is easy to show that

$$
F_{t} \equiv E\left[\sum_{s=0}^{\infty} \frac{1}{R^{S}} D_{t+s} \mid \tilde{D}_{t}, S_{t}\right]=\frac{R \bar{D}}{r}+\frac{R}{R-\alpha_{D}} \tilde{D}_{t}+\frac{1}{R-\alpha_{D}} S_{t},
$$

and that the innovation variance of $F_{t}, \sigma_{F}^{2}$, is given by

$$
\sigma_{F}^{2}=\frac{R^{2}}{\left(R-\alpha_{D}\right)^{2}} \sigma_{\epsilon}^{2}+\frac{1}{\left(R-\alpha_{D}\right)^{2}} \sigma_{S}^{2}
$$

In the case that investors are risk neutral, $F_{t}-D_{t}$ gives the equilibrium ex-dividend price of the stock. When investors are risk averse, however, the equilibrium price will depend on the risk aversion of the market.

Define a variable $Z_{t}$ that can be interpreted as the risk aversion 
of the marginal investor in the market:

$$
Z_{t} \equiv \frac{a b_{t}}{(1-\omega) a+\omega b_{t}} .
$$

Let $Z_{t}=\bar{Z}+\bar{Z}_{t}$. We assume that $\tilde{Z}_{t}$ follows an $\operatorname{AR}(1)$ process:

$$
\tilde{\mathrm{Z}}_{t}=\alpha_{Z} \tilde{\mathrm{Z}}_{t-1}+u_{Z, t}, \quad 0 \leq \alpha_{Z} \leq 1 .
$$

We also assume that $u_{Z, t}$ is independent of other shocks and is i.i.d. normal: $u_{Z, t} \sim \mathscr{N}\left(0, \sigma_{Z}^{2}\right)$. This assumption allows $Z_{t}$, and thus $b_{t}$, to be negative. This could be avoided, however, if we replaced the exponential utility assumption (1) by the assumption that investors have mean-variance preferences; that is, they maximize the objective function $E_{t} W_{t+1}-\Psi \operatorname{var}_{t} W_{t+1} / 2$. All the results in the paper would follow, and we could restrict the $Z_{t}$ process to be bounded away from zero.

Finally, we assume that $\sigma_{Z}^{2} \leq \sigma_{Z}^{* 2} \equiv\left(R-\alpha_{Z}\right)^{2} / 4 \sigma_{F}^{2}$. This assumption is used to derive an equilibrium price function where the price of the stock is a decreasing function of the aggregate risk aversion $Z_{t}$.

THEorem 1. For the economy defined above, there exists an equilibrium price of the stock that has the following form:

$$
P_{t}=F_{t}-D_{t}+\left(p_{0}+p_{Z} Z_{t}\right) \text {, }
$$

where $p_{Z}=-\left(\left(R-\alpha_{Z}\right) / 2 \sigma_{Z}^{2}\right)\left[1-\sqrt{1-\left(\sigma_{Z}^{2} / \sigma_{Z}^{* 2}\right)}\right]$ and $p_{0}=$ $\left(1-\alpha_{Z}\right) p_{Z} \bar{Z} / r<0$.

Proof of Theorem 1. See Appendix A.

\section{Excess Stock Returns and Trading Volume}

The excess return per share on the stock realized at time $t+1$ is written as $Q_{t+1} \equiv P_{t+1}+D_{t+1}-R P_{t}$. Given the equilibrium price, the expected excess return anticipated by investors in period $t$, denoted by $e_{t}$, is

$$
e_{t} \equiv E\left[Q_{t+1} \mid \mathscr{I}_{t}\right]=\sigma_{Q}^{2} Z_{t}, \quad \sigma_{Q}^{2}=\sigma_{F}^{2}+p_{Z}^{2} \sigma_{Z}^{2},
$$

where $\sigma_{Q}^{2} \equiv \operatorname{var}\left[Q_{t+1} \mid \mathscr{I}_{t}\right]$. Then, we have

$$
Q_{t+1}=e_{t}+\kappa\left\{e_{t+1}-E_{t}\left[e_{t+1}\right]\right\}+\left\{F_{t+1}-E_{t}\left[F_{t+1}\right]\right\},
$$

where $\kappa=p_{Z} / \sigma_{Q}^{2}$. Equation (8) states that the unexpected excess stock return per share has two components: innovations in expected excess returns per share and innovations in expected future 
cash flows per share. Given the return process (9), the serial correlation in returns can be easily calculated:

$$
\rho_{Q_{t}, Q_{t+1}}=\frac{1}{\sigma_{Q}^{2}} \operatorname{cov}\left[Q_{t}, Q_{t+1}\right]=-\frac{\left(R-\alpha_{Z}\right)\left(1-\alpha_{Z} R\right) p_{Z}^{2}}{1-\alpha_{Z}^{2}} \frac{\sigma_{Z}^{2}}{\sigma_{Q}^{2}}
$$

Clearly, $\rho_{Q_{t}}, Q_{t+1}$ is positive if $\alpha_{Z}>1 / R$ and is negative if $\alpha_{Z}<1 / R$. Let $X_{t}^{a}$ and $X_{b}^{a}$ be, respectively, the optimal stock holdings of type $A$ and type B investors. The solution of the optimization problem (1) yields

$$
\begin{aligned}
& X_{t}^{a}=\frac{E\left[Q_{t+1} \mid P_{t}, D_{t}, S_{t}\right]}{a \operatorname{var}\left[Q_{t+1} \mid P_{t}, D_{t}, S_{t}\right]}=\frac{1}{a} Z_{t}, \\
& X_{t}^{b}=\frac{E\left[Q_{t+1} \mid P_{t}, D_{t}, S_{t}\right]}{b_{t} \operatorname{var}\left[Q_{t+1} \mid P_{t}, D_{t}, S_{t}\right]}=\frac{1}{b_{t}} Z_{t} .
\end{aligned}
$$

Changes in investors' preferences relative to one another generate trading. $X_{t}^{a}$ (and $X_{t}^{b}$ ) change as $Z_{t}$ changes:

$$
X_{t}^{a}-X_{t-1}^{a}=(1 / a)\left(Z_{t}-Z_{t-1}\right) .
$$

Trading volume is then

$$
V_{t}=\omega\left|X_{t}^{a}-X_{t-1}^{a}\right|=(\omega / a)\left|Z_{t}-Z_{t-1}\right| .
$$

Given the $Z_{t}$ process, mean trading volume is $\bar{V} \equiv E\left[V_{t}\right]=\left(2 \omega \sigma_{Z}\right) /$ $\left(a \sqrt{\pi\left(1+\alpha_{Z}\right)}\right.$. Equation (13) completes the solution of the model for the joint behavior of volume and stock returns.

\section{IMPLications OF THE MODEl For VOLUMe AND SERIAL CORRELATION}

Investors in the economy have perfect information about the current level of $Z_{t}$. They can use $Z_{t}$ to predict future excess returns as shown by equation (7). When $Z_{t}$ is high, the type B investors are highly risk averse and less willing to hold the stock. The price of the stock has to adjust to increase the expected future excess return so that the type A investors are induced to hold more of the stock.

We, as econometricians, do not directly observe $Z_{t}$ or $S_{t}$. We observe only realized excess returns and trading volume. ${ }^{10}$ However, these variables do provide some information about the

10. We could actually use a finer information set containing dividends, prices, and volume. This would improve our inferences about $Z_{t}$. For simplicity, however, we use only excess returns and volume in this paper. 
current level of $Z_{t}$ and can help predict future returns. A low return due to a drop in the price could be caused either by an increase in $Z_{t}$ or by a low realization of $S_{t}$, i.e., bad news about future cash flow. However, changes in $Z_{t}$ will generate trading among investors, while public news about future cash flows will not. Therefore, low returns accompanied by high trading volume are more likely due to increases in $Z_{t}$ while those accompanied by low trading volume are more likely due to low realizations of $S_{t}$. In the case of an increase in $Z_{t}$, the expected excess return for next period will be high, while for the case of low $S_{t}$, it will not. Thus, the autocorrelation of the stock return should decline with trading volume.

\section{A. Analytical Results}

In this subsection we use analytical methods to develop this intuition more formally. In the next subsection we use simulation methods to a similar end.

We want to calculate the predictable component in the excess return based on the current return and volume: $E\left[Q_{t+1} \mid Q_{t}, V_{t}\right]=$ $\sigma_{Q}^{2} E\left[Z_{t} \mid Q_{t}, V_{t}\right]$. The following theorem holds.

THEOREM 2. Under the assumptions we have made about the structure of the economy and the distribution of shocks, we have

$$
E\left[\tilde{Q}_{t+1} \mid Q_{t}, V_{t}\right]=\phi_{Q} \tilde{Q}_{t}-\phi_{V} \tanh \left(\theta V_{t} \tilde{Q}_{t}\right) V_{t} .
$$

A quadratic approximation to equation (14) is

where $\left(\theta \phi_{V}\right)>0$.

$$
E\left[Q_{t+1} \mid Q_{t}\right]=\left(\phi_{Q}-\theta \phi_{V} V_{t}^{2}\right) Q_{t},
$$

\section{Proof of Theorem 2. See Appendix B.}

In order to understand the results in Theorem 2, first consider the case where volume $V_{t}=0$. In this case, there is no change in the investors' relative risk aversion (i.e., $Z_{t}$ has remained the same). Hence, there should be no change in the expected excess return from the previous period. The realized excess return approximates the expected excess return in the previous period. Thus, $E\left[\tilde{Q}_{t+1} \mid Q_{t}, V_{t}=0\right]=\phi_{Q} \tilde{Q}_{t}$.

Now consider the case where volume is not zero. This implies that a risk preference shock has occurred. Note that if $\tilde{Q}_{t}=0$ (i.e., there were no unusual date $t$ returns), then $E\left[\tilde{Q}_{t+1} \mid Q_{t}=0, V_{t}\right]=0$, 
independent of the value of $V_{t}$. Although volume implies that $\tilde{Z}_{t}$ is different from $\tilde{Z}_{t-1}$, it does not reveal the direction of the change. If $\tilde{Q}_{t}$ is negative, however, we can infer that $\tilde{Z}_{t}$ is more likely to have increased than decreased, and thus the expected value of $Z_{t}$ is high. Given a negative $\tilde{Q}_{t}$, the higher is $V_{t}$, the higher is the implied value of $\tilde{Z}_{t}$.

We can re-express equation (15) in a form that looks more similar to the regression equations used in the previous section:

$$
E\left[\tilde{Q}_{t+1} \mid Q_{t}, V_{t}\right]=\left(\phi_{0}-\phi_{1} \tilde{V}_{t}\right) \tilde{Q}_{t},
$$

where $\phi_{1}$ is positive while the sign of $\phi_{0}$ is ambiguous. (See Appendix B.)

In Theorem 2 we only consider how current volume in addition to the current return can help in predicting future returns. In principle, we could use the whole history of returns and volume to forecast future returns. Let $\mathcal{I}_{t}^{*}=\left\{Q_{\tau}, V_{\tau}: \tau \leq t\right\}$ be the information set that contains the history of excess returns and volume up to and including period $t$. The forecasting problem faced by an econometrician is to calculate the conditional expectation: $E\left[Q_{t+1} \mid \mathscr{F}_{t}^{*}\right]=\sigma_{Q}^{2} E\left[Z_{t} \mid \mathscr{F}_{t}^{*}\right]$. This is a nonlinear filtering problem for which there is no simple solution. We could calculate the conditional expectation iteratively: having calculated the expectation conditional on the return and volume in the current period, we could calculate the expectation conditional on the return and volume in the current and the previous period, and so on [Wang, 1993a]. This process would reveal higher-order dynamic relations between return and volume, which could be related to empirical work like that of Brock, Lakonishok, and LeBaron [1992]. However, this is outside the scope of the current paper.

Theorem 2 provides some justification for the exploratory regressions we reported in the empirical section of the paper. The theorem states that aggregate risk aversion (and hence the expected stock return) is related to the lagged stock return and to the lagged return interacted with volume. The coefficient on the volume-weighted lagged return should be negative, as we found in the data. Note that there is some slippage between the theoretical variables in our model and the variables measured in our empirical work. The model generates predictions about the level of turnover and the serial correlation of returns per share, while our empirical work concerns the detrended $\log$ of turnover and the serial correlation of log returns per dollar invested. 


\section{B. Simulation Results}

Although the analysis of the previous subsection makes our basic point, that volume and serial correlation should be negatively related in our heterogeneous-agent model, it is not clear whether this effect is quantitatively important for plausible parameter values. In this subsection we run some simple simulations to address this question. The model of Section III, with normal driving processes, is straightforward to simulate because it is a linear model conditional on investors' information. It only becomes nonlinear when we condition on the smaller information set containing volume and returns alone. The key question is how to calibrate the parameters of the model.

We begin by describing the riskless and risky assets in the economy. We set the riskless interest rate $R$ equal to 1.01 at an annual rate, or 1.00004 at a daily rate assuming that there are 250 trading days in a year. We set the autoregressive parameter for the stock dividend, $\alpha_{D}$, equal to one. This makes the dividend a random walk. In daily data any plausible dividend process will have $\alpha_{D}$ very close to one, and the model is simplified by setting it equal to one. Next we normalize the stock price so that it equals one when all the stochastic terms equal zero, and set stochastic terms to zero at the beginning of our simulations. This normalization means that the average stock price should not be too far from one during our simulation periods, although the stock price process has a unit root so there is no fixed mean. The normalization makes absolute price variability close to percentage price variability, and it ensures that the coefficient of absolute risk aversion and the coefficient of relative risk aversion are similar if initial riskless asset holdings are small. ${ }^{11}$

The next step is to pick a plausible value for the innovation variance $\sigma_{F}^{2}$ of the stock's fundamental value $F_{t}$. We choose $\sigma_{F}^{2}=$ $(0.01)^{2}$, so that the standard deviation of the daily stock return (in the absence of shifting risk aversion) is 1 percent. This is a little higher than the average in postwar data. Equation (4) gives the implications of this choice for the variances of the dividend signal $S_{t}$ and the contemporaneous dividend innovation $\epsilon_{t}$. If there is no dividend signal, then $\sigma_{S}^{2}=0$, and the implied variance of the dividend innovation $\epsilon_{t}$ is $\sigma_{\epsilon}^{2}=(R-1)^{2} \sigma_{F}^{2} / R^{2}$. If all dividend

11. Note that riskless asset holdings of the agents are not identified by the model. With exponential utility, these holdings do not affect demand for the risky asset. 
information is received one day in advance, then $\sigma_{\epsilon}^{2}=0$, and $\sigma_{S}^{2}=$ $(R-1)^{2} \sigma_{F}^{2}$. The simulation results are only trivially affected by varying the relative importance of the dividend signal and the contemporaneous dividend innovation.

We now turn to the specification of the two groups of investors. Suppose initially that both groups have the same average risk aversion coefficient. Then this coefficient can be identified from the stock demand equation (11). When all investors have constant risk aversion $a$, then (11) implies that $a=E\left[Q_{t+1}\right] / \operatorname{var}\left[Q_{t+1}\right]$. If stock price equals fundamental value, then $\operatorname{var}\left[Q_{t+1}\right]=\sigma_{F}^{2}=(0.01)^{2}$. Setting $a=3$ gives a reasonable value for $E\left[Q_{t+1}\right]$ of 0.0003 , or 7.5 percent at an annual rate. This procedure for estimating average risk aversion is a variant of that proposed by Friend and Blume [1975].

Next we consider $\omega$, the proportion of market-making agents. Given the $Z_{t}$ process, this parameter plays two roles. First, in equation (13) the trading volume generated by a given shift in $Z_{t}$ is proportional to $\omega / a$. Second, in equation (5) the mapping between $Z_{t}$ and the risk aversion of liquidity traders $b_{t}$ is determined by $\omega$. When $\omega$ is small, $Z_{t}$ moves almost one-for-one with $b_{t}$; when $\omega$ is large, on the other hand, large shifts in $b_{t}$ result in smaller changes in $Z_{t}$.

It turns out that if we set $a=3$, then we must also pick a very small value of $\omega, 0.0005$. Figure I shows that turnover is typically 0.5 percent or less. In exploratory simulations with larger values of $\omega$, the variation in $Z_{t}$ required to explain the effect of volume on autocorrelation generates too much trading volume when marketmakers have risk aversion $a=3$. We can, however, increase the fraction of market-makers if we also make market-makers more risk averse, since volume is determined by the ratio $\omega / a$. We obtain almost identical simulation results, for example, if we set $\omega=0.005$ and $a=30$, while keeping the mean of $Z_{t}$ equal to 3 to match the mean stock return.

The trickiest part of the calibration is to specify the dynamics of the $Z_{t}$ process. We would like to pick a process that generates realistic stock price behavior. Equation (6) gives the price innovation variance as $p_{Z}^{2} \sigma_{Z}^{2}+\sigma_{F}^{2}$. Unfortunately, the coefficient $p_{Z}$ is itself a function of $\sigma_{Z}^{2}$ and the other parameters of the model. When $\sigma_{Z}^{2}=$ 0 , however, Appendix A shows that $p_{Z}=p_{Z}(0) \equiv-\sigma_{F}^{2} /\left(R-\alpha_{Z}\right)$. The coefficient $p_{Z}(0)$ is the value of $p_{Z}$ that obtains when $Z$ is deterministic. As a simple way to calibrate the model, we define a coefficient $\lambda$ equal to the standard deviation of price innovations 
caused by randomness in $Z$ divided by the standard deviation of innovations in fundamental value, evaluated using $p_{Z}(0)$ :

$$
\lambda \equiv \frac{p_{Z}(0) \sigma_{Z}}{\sigma_{F}}=\frac{\sigma_{F} \sigma_{Z}}{R-\alpha_{Z}} .
$$

Solving this equation for $\sigma_{Z}^{2}$, we find that

$$
\sigma_{Z}^{2}=\lambda^{2}\left(R-\alpha_{Z}\right)^{2} / \sigma_{F}^{2} .
$$

This equation can be substituted into the condition that $\sigma_{Z}^{2} \leq \sigma_{Z}^{* 2}$, which guarantees a real solution for the coefficient $p_{z}$. We can then restate that condition in the simple form $\lambda \leq 0.5$. Thus, only limited extra stock price variability can be generated by shifting risk aversion.

In preliminary simulations, we varied $\lambda$ over the permissible range from 0 to 0.5 , while at the same time varying the persistence parameter $\alpha_{Z}$ over its permissible range from 0 to 1 . We found a strong negative relation between trading volume and the first return autocorrelation only for $\lambda$ values above about 0.2 , and $\alpha_{Z}$ values below about 0.5 . With smaller values of $\lambda$, shifting risk aversion did not have a sufficient effect on stock price behavior to be readily detectable, even with very large numbers of observations. With larger values of $\alpha_{Z}$, price changes caused by changing risk aversion are largely permanent so trading volume does not strongly signal that price movements will be reversed. For the final simulations reported below, we picked $\lambda=0.25$ and $\alpha_{Z}=0,0.25$, and 0.5 .

Once we have chosen parameter values, we can solve for the price coefficients $p_{0}$ and $p_{Z}$. The final step is to choose an initial dividend $D_{0}$ to meet our requirement that the initial price equal one. We then draw normal innovations with the appropriate variances and create artificial data on stock prices and trading volume. We create series that have 3000 observations (roughly the number of observations in our 1962-1974 and 1975-1987 subsamples) after discarding the first 100 observations.

Illustrative simulation results are reported in Table XI. The table shows regression results for a standard AR(1) return model and for our model interacting the return with trading volume. All parameters are fixed as described above, except for the parameter $\alpha_{Z}$ which describes the persistence of shifts in risk aversion. This parameter is 0 in panel A of Table XI, 0.25 in panel B, and 0.5 in panel C. In panel A we find a strong effect of volume on the first autocorrelation of returns. The $t$-statistic on volume is 3.67 , and 
TABLE XI

Simulations of Volume and the First Autocorrelation

$r_{t+1}=\alpha+\left(\beta+\gamma_{1} V_{t}\right) r_{t}$

\begin{tabular}{lccc}
\hline \hline & $\beta$ & $\gamma_{1}$ & \\
Specification & $(t)$ & $(t)$ & $R^{2}$ \\
\hline A: $\alpha_{z}=0$ & & & \\
AR(1) & -0.082 & & 0.007 \\
& $(4.50)$ & $(3.67)$ & 0.011 \\
Volume & 0.009 & & \\
& $(0.307)$ & & 0.001 \\
B: $\alpha_{z}=0.25$ & & & 0.005 \\
AR(1) & -0.036 & $(3.45)$ & \\
& $(2.03)$ & & 0.000 \\
Volume & 0.051 & & 0.001 \\
& $(0.165)$ & & \\
C: $\alpha_{2}=0.5$ & & $(1.26)$ & \\
AR $(1)$ & -0.005 & & \\
Volume & $(0.261)$ & & \\
& 0.024 & & \\
\hline \hline
\end{tabular}

the addition of volume to the regression increases the $R^{2}$ statistic by more than 50 percent (although of course the $R^{2}$ remains very low in absolute terms). The coefficient on volume is -16.2 , while the standard deviation of volume (not shown in the table) is 0.0036 . Thus, when volume moves from two standard deviations below the mean to two standard deviations above, the autocorrelation of the stock return falls by 0.23 , an economically significant amount.

As the persistence of risk aversion increases, the relation between volume and autocorrelation weakens. Results in panel B are only slightly weaker than those in panel $\mathrm{A}$, but in panel $\mathrm{C}$ the coefficient on volume is statistically insignificant although the point estimate is still negative. Even with $\alpha_{Z}=0.5$, the half-life of a shift in risk aversion is only one trading day, so it is clear that risk aversion shifts must be highly transitory for our model to fit the data.

A related problem for our model is that the parameter values in Table XI imply extreme movements in average risk aversion $Z_{t}$. The simulation reported in panel A has a sample average for $Z_{t}$ of 3.42 , close to the population value of 3 . The sample standard deviation is 25.2, with a minimum of -89 and a maximum of 88 . Given that market-makers are assumed to be a very small fraction 
of the market, the implied movements of liquidity traders' risk aversion $b_{t}$ are almost equal to those of $Z_{t}$. (As noted above, a larger value of $\omega$ would imply larger movements in $b_{t}$ relative to $Z_{t}$, worsening this problem.) As $\alpha_{Z}$ increases, the movements in $Z_{t}$ are slightly dampened, but they remain extreme even when $\alpha_{Z}=0.5$. The sample average $Z_{t}$ in panel $\mathrm{C}$ is 2.80 , with a standard deviation of 14.4 , a minimum of -46 , and a maximum of 57 .

This difficulty arises for the following reason. Persistent shifts in $Z_{t}$ have large effects on prices, but as noted above, they do not generate a strong high-frequency relationship between volume and serial correlation. Volume interacted with the lagged stock return helps to identify the recent change in the expected stock return; but this is not a good guide to the current level of the expected stock return when the expected return follows a persistent time series process. Transitory shifts in $Z_{t}$, on the other hand, have small effects on prices because small temporary price movements can create large temporary changes in expected returns. Equation (18) shows that as the persistence parameter $\alpha_{Z}$ falls, $Z_{t}$ must become more variable for any given price impact parameter $\lambda$. Thus, to get a strong effect of volume on serial correlation, we need very large transitory shifts in risk aversion. This is an example of the well-known fact that high-frequency predictability in asset returns is hard to explain using a frictionless model with utilitymaximizing risk-averse agents. Our model has an advantage in that it allows for heterogeneous and time-varying risk aversion, but it does not entirely escape this problem.

Our model has another empirical difficulty related to persistence. We have found that the autocorrelation of stock returns depends on a detrended volume measure that is fairly persistent, having a first daily autocorrelation of about 0.7 and a fifth daily autocorrelation that still exceeds 0.5 . When one extracts the high-frequency component of volume by using an unobserved components model or subtracting a few days' moving average of volume [LeBaron, 1992b], the relation between volume and autocorrelation becomes much weaker. This contradicts the implication of our model that volume is an MA(1) process when market average risk aversion $Z_{t}$ is white noise (and close to an MA(1) process when risk aversion is a transitory AR(1) process). It should, however, be possible to generalize the model to mitigate this problem. Since volume depends on the absolute value of the change in market average risk aversion $Z_{t}$, a conditionally heteroskedastic process for $Z_{t}$ could produce persistent movements in volume. 


\section{CONCLUSION}

In this paper we have documented a striking fact about short-run stock market behavior: the first daily autocorrelation of stock returns is lower on high-volume days than on low-volume days. This phenomenon appears even in very large stock indexes and individual stock returns, so that it is unlikely to be due to nonsynchronous stock trading. We have proposed an alternative explanation relying on the idea that trading volume occurs when random shifts in the stock demand of noninformational traders are accommodated by risk-averse market-makers. If we allow large transitory shifts in noninformational demand, then our model fits many of the features of the data.

\section{Appendix A: Proof of Theorem 1}

The proof of Theorem 1 follows a fairly standard pattern. First, we conjecture that the equilibrium price function has the given form. Second, we solve the optimization problem of both type $A$ and type $B$ investors given the conjectured price function. Finally, we impose the market-clearing condition to verify the conjectured price function.

If the price function takes the conjectured form, the excess return per share of the stock, denoted by $Q_{t+1} \equiv P_{t+1}+D_{t+1}-R P_{t}$, can be expressed as

$$
Q_{t+1}=-r p_{0}+p_{Z}\left(Z_{t+1}-R Z_{t}\right)+\frac{1}{R-\alpha_{D}} S_{t+1}+\frac{R}{R-\alpha_{D}} \epsilon_{D, t+1} .
$$

The conditional distribution of the future excess return is normal and has the following moments:

$$
\begin{aligned}
E\left[Q_{t+1} \mid \mathscr{F}_{t}\right] & =-r\left(p_{0}+p_{Z} \bar{Z}\right)+p_{Z}\left(\alpha_{Z}-R\right) \tilde{Z}_{t}, \\
\operatorname{var}\left[Q_{t+1} \mid \mathscr{J}_{t}\right] & \equiv \sigma_{Q}^{2}=\sigma_{F}^{2}+p_{Z}^{2} \sigma_{Z}^{2} .
\end{aligned}
$$

Given the price function, the solution to the optimization problem (1) gives the optimal holdings of type A and type B investors:

$$
\begin{aligned}
X_{t}^{a} & =\frac{E\left[Q_{t+1} \mid P_{t}, D_{t}, S_{t}\right]}{a \operatorname{var}\left[Q_{t+1} \mid P_{t}, D_{t}, S_{t}\right]} \\
& =\frac{1}{a \sigma_{Q}^{2}}\left[-r\left(p_{0}+p_{Z} \bar{Z}\right)+\left(\alpha_{Z}-R\right) p_{Z} \tilde{Z}_{t}\right],
\end{aligned}
$$


(A.2b)

$$
\begin{aligned}
X_{t}^{b} & =\frac{E\left[Q_{t+1} \mid P_{t}, D_{t}, S_{t}\right]}{b_{t} \operatorname{var}\left[Q_{t+1} \mid P_{t}, D_{t}, S_{t}\right]} \\
& =\frac{1}{b_{t} \sigma_{Q}^{2}}\left[-r\left(p_{0}+p_{Z} \bar{Z}\right)+\left(\alpha_{Z}-R\right) p_{Z} \tilde{Z}_{t}\right]
\end{aligned}
$$

The market-clearing condition states that

$$
\omega X_{t}^{a}+(1-\omega) X_{t}^{b}=1 .
$$

Hence,

$$
\left(\frac{\omega}{a}+\frac{1-\omega}{b_{t}}\right)\left[-r\left(p_{0}+p_{Z} \bar{Z}\right)+\left(\alpha_{Z}-R\right) p_{Z} \tilde{Z}_{t}\right]=\sigma_{Q}^{2} .
$$

Since $\omega / a+(1-\omega) / b_{t}=1 / Z_{t}$, we have

$$
\left(\alpha_{Z}-R\right) p_{Z}=\sigma_{Q}^{2}, \quad-r\left(p_{0}+p_{Z} \bar{Z}\right)=\sigma_{Q}^{2} \bar{Z} .
$$

Under the condition that $\sigma_{Z}^{2} \leq \sigma_{Z}^{* 2}$, we have two real roots for $p_{Z}$ :

$$
\left(p_{Z}=\frac{R-\alpha_{Z}}{2 \sigma_{Z}^{2}}\left[-1 \pm \sqrt{1-\left(\sigma_{Z}^{2} / \sigma_{Z}^{* 2}\right)}\right] .\right.
$$

For $\alpha_{Z}<1$, both roots are negative. We choose the root that gives the right limit when $\sigma_{F}^{2}$ goes to zero. In the case that $\sigma_{F}^{2} \rightarrow 0, p_{Z}$ should go to zero. This leads to the solution for $p_{Z}$ which is the root with the positive sign. $p_{0}$ is then given by $p_{0}=\left(1-\alpha_{Z}\right) p_{Z} \bar{Z} / r$.

\section{Appendix B: Proof of Theorem 2}

Define $\Delta_{t} \equiv(\omega / a)\left(Z_{t}-Z_{t-1}\right)$. Thus, $V_{t}=\left|\Delta_{t}\right|$. Also, define $\epsilon_{F, t}$ $=F_{t}-E_{t-1}\left[F_{t}\right] . \epsilon_{F, t}$ gives the innovation process to $F_{t}$. Then,

$$
Q_{t+1}=p_{Z}\left(Z_{t+1}-Z_{t}\right)+\epsilon_{F, t+1} .
$$

Let $\Sigma$ be the covariance matrix of $\left(Q_{t}, \Delta_{t}\right)$.

LEMMA. Given that $\tilde{Q}_{t+1}, \bar{Q}_{t}$ and $\Delta_{t}$ are jointly normal, we have where

$$
\theta=-\frac{(\omega / a)}{|\Sigma|} \sigma_{Q_{t}, \Delta_{t}}, \phi_{Q}=\frac{(\omega / a)^{2}}{|\Sigma|}\left(\sigma_{Q_{t+1}, Q_{t}} \sigma_{\Delta_{t}, \Delta_{t}}-\sigma_{Q_{t+1}, \Delta_{t}} \sigma_{Q_{t}, \Delta_{t}}\right),
$$

and

$$
\phi_{V}=\frac{(\omega / a)}{|\Sigma|}\left(\sigma_{Q_{t+1}, Q_{t}} \sigma_{Q_{t}, \Delta_{t}}-\sigma_{Q_{t+1}, \Delta_{t}} \sigma_{Q_{t}, Q_{t}}\right)
$$


Proof of Lemma. See Wang [1993a].

It is easy to show that

$$
\begin{aligned}
\sigma_{Q_{t}, Q_{t}} & =\sigma_{F}^{2}+\frac{\left(1+R^{2}-2 \alpha_{Z} R\right) p_{Z}^{2} \sigma_{Z}^{2}}{1-\alpha_{Z}^{2}}, \\
\sigma_{\Delta_{t}, \Delta_{t}} & =\left(\frac{\omega}{a}\right)^{2} \frac{2 \sigma_{Z}^{2}}{1+\alpha_{Z}} \\
\sigma_{Q_{t}, \Delta_{t}} & =\frac{\omega}{a} \frac{(1+R) p_{Z} \sigma_{Z}^{2}}{1+\alpha_{Z}} \\
\sigma_{Q_{t+1}, Q_{t}} & =\frac{\left(a_{Z}-R\right)\left(1-\alpha_{Z} R\right) p_{Z}^{2} \sigma_{Z}^{2}}{1-\alpha_{Z}^{2}} \\
\sigma_{Q_{t+1}, \Delta_{t}} & =\frac{\omega}{a} \frac{(1+R) p_{Z} \sigma_{Z}^{2}}{1+\alpha_{Z}}
\end{aligned}
$$

Hence,

$$
\begin{aligned}
\phi_{Q} & =\frac{(\omega / a)^{2}}{|\Sigma|} \frac{\left(r+\alpha_{Z}\right)\left(R-\alpha_{Z}\right) p_{Z}^{2} \sigma_{Z}^{4}}{\left(1+\alpha_{Z}\right)\left(1-\alpha_{Z}^{2}\right)}>0, \\
\phi_{V} & =-\frac{(\omega / a)}{|\Sigma|} \frac{\left(R-\alpha_{Z}\right) p_{Z} \sigma_{Z}^{2}}{1+\alpha_{Z}}\left[\sigma_{F}^{2}+\frac{\left(1+\alpha_{Z} R\right) r p_{Z}^{2} \sigma_{Z}^{2}}{1-\alpha_{Z}^{2}}\right], \\
\theta & =-\frac{(\omega / a)}{|\Sigma|} \frac{(1+R) p_{Z} \sigma_{Z}^{2}}{1+\alpha_{Z}} .
\end{aligned}
$$

To a quadratic approximation, equation (A.8) can be re-expressed as

$$
E\left[\tilde{Q}_{t+1} \mid \tilde{Q}_{t}, V_{t}\right]=\left[\phi_{Q}-\left(\theta \phi_{V}\right) V_{t}^{2}\right] \tilde{Q}_{t} .
$$

Clearly, $\theta \phi_{V}>0$. This completes the proof of Theorem 2. We can further write $V_{t}=\bar{V}+\bar{V}_{t}$, where $\bar{V}=E\left[V_{t}\right]$ is the mean volume. To the same order of approximation, equation (A.9) becomes

$$
\begin{aligned}
& \text { (A.10) } E\left[\tilde{Q}_{t+1} \mid \tilde{Q}_{t}, V_{t}\right]=\left(\phi_{0}-\phi_{1} \tilde{V}_{t}\right) \tilde{Q}_{t}, \\
& \text { where } \phi_{0}=\phi_{Q}-\left(\theta \phi_{V}\right) \bar{V}^{2} \text { and } \phi_{1}=2 \theta \phi_{V} \bar{V}>0 . \\
& \text { PRINCETON UNIVERSITY } \\
& \text { UNIVERSITY OF PENNSYLVANIA } \\
& \text { MASSACHUSETTS INSTITUTE OF TECHNOLOGY }
\end{aligned}
$$




\section{REFERENCES}

Brock, William A., Josef Lakonishok, and Blake LeBaron, "Simple Technical Trading Rules and the Stochastic Properties of Stock Returns," Journal of Finance, XLVII (1992), 1731-64.

Campbell, John Y., and Ludger Hentschel, "No News Is Good News: An Asymmetric Model of Changing Volatility in Stock Returns," Journal of Financial Economics, XXXI (1992), 281-318.

Campbell, John Y., and Albert S. Kyle, "Smart Money, Noise Trading, and Stock Price Behavior," Review of Economic Studies, LX (1993), 1-34.

Conrad, Jennifer, Allaudeen Hameed, and Cathy M. Niden, "Volume and Autocovariances in Short-Horizon Individual Security Returns," unpublished paper, University of North Carolina at Chapel Hill and University of Notre Dame, 1992.

Conrad, Jennifer, and Gautam Kaul, "Time-Variation in Expected Returns," Journal of Business, LXI (1988), 409-25.

De Long, J. Bradford, Andrei Shleifer, Lawrence H. Summers, and Robert J. Waldmann, "The Size and Incidence of the Losses from Noise Trading," Journal of Finance, XLIV (1989), 681-96.

De Long, J. Bradford, Andrei Shleifer, Lawrence H. Summers, and Robert J. Waldmann, "Noise Trader Risk in Financial Markets," Journal of Political Economy, XCVIII (1990), 703-38.

Duffee, Gregory, "Trading Volume and Return Reversals," Finance and Economics Discussion Series No. 192, Board of Governors of the Federal Reserve System, 1992.

Friend, Irwin, and Marshall E. Blume, "The Demand for Risky Assets," American Economic Review, LXV (1975), 900-22.

Gallant, A. Ronald, Peter E. Rossi, and George Tauchen, "Stock Prices and Volume," Review of Financial Studies, V (1992), 199-242.

Grossman, Sanford J., and Merton H. Miller, "Liquidity and Market Structure," Journal of Finance, XLIII (1988), 617-33.

Grossman, Sanford J., and Zhongquan Zhou, "Optimal Investment Strategies for Controlling Drawdowns," unpublished paper, University of Pennsylvania, 1992.

Harris, Lawrence, "Transactions Data Tests of the Mixture of Distributions Hypothesis," Journal of Financial and Quantitative Analysis, XXII (1987), $127-41$.

Jain, Prem C., and Gun-Ho Joh, "The Dependence Between Hourly Prices and Trading Volume," Journal of Financial and Quantitative Analysis, XXIII (1988), 269-83.

Jones, Charles M., Gautam Kaul, and Marc L. Lipson, "Transactions, Volume, and Volatility," unpublished paper, University of Michigan, 1991.

Karpoff, Jonathan M., "The Relation Between Price Changes and Trading Volume: A Survey," Journal of Financial and Quantitative Analysis, XXII (1987), $109-26$.

Lamoureux, Christopher G., and William D. Lastrapes, "Heteroskedasticity in Stock Return Data: Volume versus GARCH Effects," Journal of Finance, XLV (1990), 221-29.

LeBaron, Blake, "Some Relations Between Volatility and Serial Correlation in Stock Market Returns," Journal of Business, LXV (1992a), 199-219.

"Persistence of the Dow Jones Index on Rising Volume," unpublished paper, University of Wisconsin, $1992 \mathrm{~b}$.

Lo, Andrew W., and A. Craig MacKinlay, "Stock, Prices Do Not Follow Random Walks: Evidence from a Simple Specification Test," Review of Financial Studies, I (1988), 41-66.

Lo, Andrew W., and A. Craig MacKinlay, "An Econometric Analysis of Nonsynchronous Trading," Journal of Econometrics, XLV (1990), 181-211.

Morse, Dale, "Asymmetrical Information in Securities Markets and Trading Volume," Journal of Financial and Quantitative Analysis, XV (1980), 112946.

Mulherin J. Harold, and Mason S. Gerety, "Daily Trading Volume on the NYSE During the Twentieth Century," unpublished paper, Clemson University, 1989. 
Nelson, Daniel B., "Filtering and Forecasting with Misspecified ARCH Models I: Getting the Right Variance with the Wrong Model," Journal of Econometrics, LII (1992), 61-90.

Schwert, G. William, "Why Does Stock Market Volatility Change Over Time?" Journal of Finance, XLIV (1989), 1115-53. "Indexes of U. S. Stock Prices from 1802 to 1987," Journal of Business, LXIII (1990), 399-426.

Sentana, Enrique, and Sushil Wadhwani, "Feedback Traders and Stock Return Autocorrelations: Evidence from a Century of Daily Data," Economic Journal, CII (1992), 415-25.

Shiller, Robert J., "Stock Prices and Social Dynamics," Brookings Papers on Economic Activity (1984), 457-98.

Tauchen, George E., and Mark Pitts, "The Price Variability-Volume Relationship on Speculative Markets," Econometrica, LI (1983), 485-505.

Wang, Jiang, "A Model of Competitive Stock Trading Volume," unpublished paper, Sloan School, Massachusetts Institute of Technology, 1993a.

Wang, Jiang, "A Model of Intertemporal Asset Prices Under Asymmetric Information," Review of Economic Studies, LX (1993b), forthcoming.

White, Halbert, Asymptotic Theory for Econometricians (Orlando, FL: Academic Press, 1984). 
Copyright of Quarterly Journal of Economics is the property of MIT Press and its content may not be copied or emailed to multiple sites or posted to a listserv without the copyright holder's express written permission. However, users may print, download, or email articles for individual use. 